\title{
Current schizophrenia Third edition
}

\section{Editors}

Martin Lambert, Dieter Naber

Department of Psychiatry and Psychotherapy

Center for Psychosocial Medicine, University Medical Center Hamburg-Eppendorf Germany

Contributors

Eóin Killackey, Patrick McGorry

ORYGEN Research Centre

Department of Psychiatry, University of Melbourne, Victoria

Australia

\section{Steffen Moritz, Ingo Schäfer, Britta Galling, Liz Rietschel \\ Department of Psychiatry and Psychotherapy \\ Center for Psychosocial Medicine, University Medical Center Hamburg-Eppendorf \\ Germany}

\section{Tim Lambert}

Psychological Medicine, Concord Clinical School, University of Sydney

Australia

\section{Philippe Conus}

Department of Psychiatry

Centre Hospitalier Universitaire Vaudois and University of Lausanne

Switzerland

\section{Frauke Schultze-Lutter, Benno Schimmelmann}

Bern Early Recognition and Intervention Centre

University Hospital of Child and Adolescent Psychiatry Bern

Switzerland

\section{Stephan Ruhrmann}

Early Recognition and Intervention Center

Department of Psychiatry and Psychotherapy of the University of Cologne Germany

\section{Springer Healthcare}


Published by Springer Healthcare Ltd, 236 Gray's Inn Road, London, WC1X 8HB, UK.

www.springerhealthcare.com

(C) 2012 Springer Healthcare, a part of Springer Science+Business Media.

First edition published in 2005

Second edition published in 2009

All rights reserved. No part of this publication may be reproduced, stored in a retrieval system or transmitted in any form or by any means electronic, mechanical, photocopying, recording or otherwise without the prior written permission of the copyright holder.

British Library Cataloguing-in-Publication Data.

A catalogue record for this book is available from the British Library.

ISBN 978-1-908517-46-3

Although every effort has been made to ensure that drug doses and other information are presented accurately in this publication, the ultimate responsibility rests with the prescribing physician. Neither the publisher nor the authors can be held responsible for errors or for any consequences arising from the use of the information contained herein. Any product mentioned in this publication should be used in accordance with the prescribing information prepared by the manufacturers. No claims or endorsements are made for any drug or compound at present under clinical investigation.

Project editor: Alla Zarifyan

Designer: Joe Harvey

Artworker: Sissan Mollerfors

Production: Marina Maher

Printed in Great Britain by Latimer Trend 


\section{Contents}

Biographies vii

Preface xiii

Dedication xiv

1 Introduction 1

Martin Lambert and Dieter Naber

References 3

2 Current topics $\quad 5$

Early detection and treatment of patients symptomatically

at-risk for psychosis $\quad 5$

Frauke Schultze-Lutter, Stephan Ruhrmann, Benno Schimmelmann

First-episode psychosis

Eóin Killackey

Cognitive dysfunctions in schizophrenia

Steffen Moritz

Suicidality in schizophrenia

Martin Lambert

Nonadherence and service disengagement in schizophrenia

Britta Galling, Liz Rietschel, Martin Lambert

Co-occurring substance abuse in schizophrenia

Martin Lambert

Childhood trauma in schizophrenia

Ingo Schäfer and Philippe Conus

New antipsychotics and antipsychotic formulations

Tim Lambert

References 


\section{Organization of care and treatment}

General principles of care

Martin Lambert and Dieter Naber

Phase-specific treatments for schizophrenia

Martin Lambert and Dieter Naber

Management of significant side effects and physical illness

Martin Lambert

The most recommended psychosocial interventions

Eóin Killackey and Pat McGorry

References

\section{Quick reference}

Martin Lambert and Dieter Naber

Epidemiology, etiology, and course of illness

Presentations and diagnosis

References

\section{Further reading}

Behavioral emergencies

Childhood trauma

Childhood-onset schizophrenia

Classifications of psychotic disorders

Duration of antipsychotic treatment

Early intervention and prodromal schizophrenia

Electroconvulsive therapy

Epidemiology and etiology

First-episode psychosis

Late-onset schizophrenia

New antipsychotics and new antipsychotic formulations

Neuropsychological dysfunctions

Nonadherence and service disengagement

Pharmacological treatments

Pregnancy and postpartum treatment

Psychosocial treatments

Relapse prevention 
$\begin{array}{lr}\text { Schizophrenia guidelines } & 188\end{array}$

$\begin{array}{ll}\text { Shared decision-making and motivational interviewing } & 189\end{array}$

$\begin{array}{ll}\text { Side effects } & 189\end{array}$

$\begin{array}{ll}\text { Somatic diseases } & 191\end{array}$

$\begin{array}{ll}\text { Substance use disorders } & 191\end{array}$

$\begin{array}{ll}\text { Suicidal behavior } & 192\end{array}$

$\begin{array}{ll}\text { Switching antipsychotics } & 192\end{array}$

$\begin{array}{ll}\text { Treatment-resistant schizophrenia } & 193\end{array}$ 


\section{Biographies}

\section{Editors}

Martin Lambert is a professor of psychiatry at the University of Hamburg, where he is the head of the Psychosis Center, which includes the Psychosis Early Detection and Intervention Center (PEDIC). He performed his psychiatric training at the Department of Psychiatry and Psychotherapy at the University Medical Center in Hamburg, Germany. During his training, he spent 2 years at the Early Psychosis Prevention and Intervention Centre (EPPIC) in Melbourne, Australia. Professor Lambert's current research interests include the pharmacological and psychosocial treatment of schizophrenic, bipolar, and first-episode psychosis patients, and, especially, aspects of integrated care, remission and recovery, quality of life, and subjective wellbeing. Professor Lambert is the head of the network for a better mental health in Hamburg, which was founded by the German Research Association. He is the editor and author of several books about schizophrenia and has published various articles on schizophrenia and first-episode psychosis.

Dieter Naber has been the director of the Psychiatric University Hospital in Hamburg, Germany, since 1995. After studying medicine in Göttingen and Bonn, Germany, Professor Naber worked at the Psychiatric Hospital of the University of Munich, Germany, from 1977 to 1995 as a ward doctor and then as a senior physician. In 1987, he gained a postdoctoral lecturing qualification with his lecture "The etiological and therapeutic significance of endorphins in endogenous psychosis." Professor Naber conducted research during two periods at the National Institute of Mental Health, in 1978-1980 and again in 1984-1985. His current research concentrates on long-term neuroleptic treatment, efficacy and side effects of second-generation neuroleptics, and the subjective effects of neuroleptics. 


\section{Contributors}

Eóin Killackey is an associate professor and clinical psychologist at the ORYGEN Youth Health Research Centre and the Centre for Youth Mental Health at the University of Melbourne, Australia. He completed his doctorate at Deakin University in Melbourne in 2000 and has worked as a clinical psychologist in adolescent and adult public mental health settings. His research primarily focuses on psychological and pychosocial interventions in first-episode psychosis, specifically on functional recovery in first-episode psychosis, with a particular emphasis on vocational rehabilitation. Dr Killackey is also interested in evidence-based interventions in mental health and barriers to their implementation. $\mathrm{He}$ is a founder of the International First Episode Vocational Recovery group and was awarded the Organon Research Award in 2008 by the Australian Society for Psychiatric Research.

Pat McGorry is the director of the ORYGEN Youth Health and Research Centre, at the University of Melbourne, Australia. He has contributed significantly to research in the area of early psychosis over the past 16 years. During this time, he has played an integral role in the development of service structures and treatments specifically targeting the needs of young people with emerging or first-episode psychosis. In the past 2 years, he has published over 50 articles and chapters. Professor McGorry is the president of the International Early Psychosis Association and an executive board member of the International Society for Psychological Treatments in Schizophrenia and Related Psychosis. He is also a member of the organizing committee of the World Psychiatric Association Section on Schizophrenia, the advisory board of the University of California, Los Angeles Center for the Assessment and Prevention of Prodromal States, the editorial board of Schizophrenia Research, and the advisory editorial board of the Journal of Psychiatrie Sciences Humaines Neurosciences.

Steffen Moritz is an associate professor at the Center for Psychosocial Medicine at the University Hospital Hamburg-Eppendorf, Germany. He is an active researcher in the fields of neuropsychology and metacognition 
with a main focus on schizophrenia and obsessive-compulsive disorders. After receiving his diploma in psychology in 1997, he became a research assistant at the Psychiatric University Hospital of Hamburg, Germany, and obtained his PhD in 1999. Under the supervision of Professor Naber, Dr Moritz is in charge of the clinical neurocognitive unit of the hospital. Together with Dr Todd Woodward from Vancouver, Canada, he has developed a metacognitive training program for schizophrenia patients, which is now available in 23 different languages.

Ingo Schäfer is a research fellow and clinical lecturer at the Department of Psychiatry and Psychotherapy and the Center for Interdisciplinary Addiction Research at the University Medical Center Hamburg-Eppendorf, Germany. He is also an associate lecturer for public mental health at the Hamburg University of Applied Sciences. He studied medicine and public health at the Universities of Tübingen, Bordeaux, Lausanne, and Hamburg, and the Hamburg University of Applied Sciences, and received his doctoral degree from the University of Hamburg in 2002. Dr Schäfer's clinical and research interests include the treatment of patients with comorbid substance abuse and psychiatric disorders, trauma-related disorders, and treatment-resistant schizophrenia. During the past 10 years, he has been continuously involved in research on the consequences of psychological trauma in different populations and is leading various projects in that domain.

Britta Galling is a practicing psychiatrist and a researcher at the University Hospital Hamburg-Eppendorf. She studied medicine and social psychology at the universities of Hamburg, Bordeaux, Melbourne, and Montréal. Since 2003 Dr Galling has explored the subject of physician-patient communication - as a lecturer at the Institute of Medical Sociology at the University of Hamburg, and within her thesis "Migration, Health, and Intercultural Communication." Beside medical anthropology and intercultural psychiatry, Dr Galling's main interest is adolescent psychiatry with a focus on psychosis. At present she is working on a project in prevention, early intervention, and integrative care in adolescent psychosis. 
Liz Rietschel is a psychologist at the University Hospital HamburgEppendorf, Germany. She studied psychology at the universities of Gent, Valencia, and Trier. Her special interest is the research on the treatment, prevention, and early intervention of psychosis. She gained significant experience in the subject of physician-patient communication, as she therapeutically applies individual psycho-educational approaches and cognitive behavioral treatment strategies in her work with patients at high risk for or already suffering from psychosis.

Tim Lambert is professor of psychiatry at the Concord Clinical School at the University of Sydney in Australia. He also holds an appointment as the head of the Schizophrenia Treatment and Outcomes Research unit at the Brain and Mind Research Institute in Sydney. In addition, Dr Lambert fulfills clinical duties for the Sydney Local Health Network as the director of the Centre of Excellence in Relapse Prevention in Psychosis, and at the Concord Centre for Cardiometabolic Health in Psychosis.

Philippe Conus is a professor of psychiatry and the medical director of the Service of General Psychiatry of the Department of Psychiatry, Centre Hospitalier Universitaire Vaudois in Lausanne, Switzerland, and a senior lecturer at the University of Melbourne, Australia. He completed both trainings for internal medicine and psychiatry in Lausanne. From 2000 to 2003, Dr Conus worked as a consultant psychiatrist in the Early Psychosis Prevention and Intervention Centre in Melbourne, where he developed a specialized program for early intervention in affective psychosis and a clinical research project on first-episode mania. Since returning to Switzerland, he has been heading the service of general psychiatry as well as a specialized integrated early intervention program for psychosis (Treatment and Intervention in the Early Phase of Psychosis) combining clinical and research programs. His research interests cover clinical intervention in early psychosis, the early phase of bipolar disorders, as well as neurobiological mechanisms involved in the development of schizophrenia and pharmacogenetic determinants of side effects of atypical neuroleptics. 
Frauke Schultze-Lutter is a senior psychologist at the Research Department of the University Hospital of Child and Adolescent Psychiatry Bern, Germany, and the psychological-scientific head of the Bern Early Recognition and Intervention Center, a cooperation of the University Hospitals of Psychiatry as well as of Child and Adolescent Psychiatry Bern and the Soteria Bern. She studied clinical psychology in Göttingen, Germany, and received her PhD in clinical psychology at the Department of Psychology of the University of Cologne, Germany. Dr Schultze-Lutter's research focuses on the early detection of and intervention in at-risk states of severe mental disorders, particularly psychosis and bipolar disorders, with a special interest in very early subjective symptoms (ie, basic symptoms). She is the principle investigator of an epidemiological study on the prevalence of current at-risk criteria of psychosis and their relation to help-seeking, funded by the Swiss National Foundation. She was awarded the Gerd Huber Award for Research on the Prevention of Psychoses in 2010, is an elected board member of the International Early Psychosis Association, and an editorial board member of Clinical Neuropsychiatry and Psychosis.

Benno Schimmelmann is an assistant professor at the University Hospital of Child and Adolescent Psychiatry, University of Bern, where he is the chief physician and head of the research department. He studied medicine in Munich and Hamburg, Germany, and performed his child and adolescent psychiatric training at the Department of Child and Adolescent Psychiatry and Psychotherapy of the University Hospital Hamburg-Eppendorf. Dr Schimmelmann's current research interests focus on early detection and intervention in early-onset mental disorders, particularly early psychosis and bipolar disorder, and the genetics of attention-deficit/hyperactivity disorder and autism spectrum disorders. $\mathrm{He}$ is an associate editor of Early Intervention in Psychiatry and a junior editor of European Child and Adolescent Psychiatry.

Stephan Ruhrmann is an associate professor of psychiatry and an assistant medical director at the Department of Psychiatry and Psychotherapy of 
the University of Cologne, Germany, where he also heads the Cologne Early Recognition and Intervention Center and is the director of the Cologne Cognitive Neurophysiology Laboratory. He studied medicine in Heidelberg and Kiel, Germany, and performed his psychiatric training at the Department of Psychiatry and Psychotherapy of the University of Bonn, Germany. Dr Ruhrmann's current research interests focus on the prediction and prevention of psychosis. Related research activities comprise the development of multivariate prediction models and investigation of the neurophysiologic (ie, event-related potentials, eye tracking) aberrations characterizing at-risk and prepsychotic states. A further related field of his interests is the neurobiology and the prediction of negative symptoms. He was a coprincipal investigator and coordinator of the European Prediction of Psychosis Study, at present the largest prospective study in this field, and is an associate editor of Early Intervention in Psychiatry and an editorial board member of Neurology, Psychiatry and Brain Research. 


\section{Preface}

It is with pride and pleasure that we have produced the third edition of the book Current Schizophrenia. In line with the first two editions, this publication provides valuable information and guidance for those who are involved in the care of people who have schizophrenia and their relatives. The primary intention of the book is again to provide a tool that is helpful in the treatment and care of individuals with schizophrenia and easy to use in daily clinical practice.

Many experts have devoted numerous hours to this project. Special thanks go to Dr Eóin Killackey, Professor Steffen Moritz, Associate Professor Ingo Schäfer, Professor Philippe Conus, Dr Britta Galling, Dipl Psych Liz Rietschel, Professor Tim Lambert, Dr Frauke Schultze-Lutter, Associate Professor Stephan Ruhrmann, and Professor Benno Schimmelmann, who have been directly involved in writing and/or reviewing various parts of the book. In addition, Pat McGorry has participated indirectly through his work on the Australia and New Zealand Guidelines for the Treatment of Schizophrenia.

It is exciting to see that awareness of schizophrenia has improved and continues to grow, hopefully at a rapid pace. This is important for obtaining support for research and, of course, for those who suffer from this disorder and their families. Better understanding of the disease by the society in general will help all of those affected by schizophrenia, bringing them empathy and compassion, and maybe even saving some lives. All of the contributors to this book hope that it will help with some of the issues and challenges that schizophrenia presents, and improve the quality of life of patients and their relatives. In the interest of furthering the knowledge of schizophrenia, the authors welcome any constructive criticism and comments on the contents of this book. 


\section{Dedication}

This book is dedicated to Anna Joelle and Gabriele. 